\title{
The use of fresh frozen plasma or a concentrate of factor IX as replacement therapy before liver
} biopsy

\author{
B. G. GAZZARD, J. M. HENDERSON, AND ROGER WILLIAMS \\ From the Liver Unit, King's College Hospital and Medical School, London
}

SUMMARY Thirty patients with various types of chronic liver disease and a prothrombin time prolonged for four or more seconds who required needle liver biopsy for diagnostic purposes were given either fresh frozen plasma or a concentrate of clotting factors as a prophylactic measure.

The prothrombin time returned to within normal limits in seven of the 15 patients given the concentrate and in three of those receiving fresh frozen plasma. Levels of factors II, IX, and X showed increases of about $30 \%$ following concentrate administration; corresponding rises in the group given fresh frozen plasma were less. This was because of the smaller quantity of clotting factors administered with fresh frozen plasma and the increase in factor II and IX activity $/ \mathrm{kg}$ body weight/unit of clotting factor injected was greater when fresh frozen plasma was used. In neither group was there clinical evidence of bleeding, but it was of interest that most of the clotting factor levels, except in factor II, before biopsy were above those normally required for haemostasis.

No evidence of disseminated intravascular coagulation was found with the concentrate injection, and the most worrying finding was the appearance of HBAg some months later in three patients, two from the concentrate group and one from those given fresh frozen plasma. However, the conversion of these patients to HBAg positive may be unrelated to the clotting factor replacement therapy.

The risk of bleeding with a liver biopsy is considered to increase if the prothrombin time is prolonged more than three seconds (Sherlock, 1968). There are, however, some patients with prolonged prothrombin times in whom this investigation is needed for diagnostic purposes. Prophylactic administration of clotting factors would be expected to reduce the risks of bleeding in these patients, and for some years it has been our practice to infuse fresh frozen plasma immediately before liver biopsy. With the development of a concentrate of clotting factors which can be given as a single intravenous injection, the necessity for an indwelling intravenous catheter and the administration of the water and sodium load present in fresh frozen plasma could be avoided. Such concentrates contain a high concentration of clotting factors II, IX and X, the levels of which are all reduced in liver disease (Roberts and Cederbaum, 1972), and in this paper we describe a comparison with fresh frozen plasma in the correction of the coagulation defect in patients with a prolong-

Received for publication 3 June 1975. ed prothrombin time requiring a liver biopsy. Particular attention was paid to the possible development of intravascular coagulation following the infusion of the concentrate, as we had previously observed this in patients with fulminant hepatic failure given another concentrate preparation (Gazzard, Lewis, Pannell, Bidwell, Rizza, and Williams, 1974).

\section{Patients and Methods}

The series comprised 30 patients admitted to hospital between September 1973 and June 1974, who required liver biopsy and in whom the prothrombin time was prolonged four or more seconds. The relevant clinical data are given in table I, including the platelet count which was above $50 \times$ $10^{9} / 1$ in all instances. The first 15 patients were given $600 \mathrm{ml}$ of fresh frozen plasma intravenously over a period of half an hour, followed by a further $300 \mathrm{ml}$ six hours later. The second 15 patients were given, by slow intravenous injection, $20 \mathrm{ml}$ of a concentrate of clotting factors. This contained 2000 units of 


\begin{tabular}{|c|c|c|c|c|c|}
\hline Patient & Age $(y r)$ & Diagnosis & $\begin{array}{l}\text { Plasma Bilirubin } \\
(\mu \mathrm{mol} / \mathrm{l})\end{array}$ & $\begin{array}{l}\text { Aspartate Amino- } \\
\text { transferase }(\mathrm{iu} / \mathrm{l})\end{array}$ & $\begin{array}{l}\text { Platelet Count } \\
\left(/ l \times 10^{9}\right)\end{array}$ \\
\hline \multicolumn{6}{|c|}{ Given Fresh Frozen Plasma } \\
\hline 1 & 38 & Active chronic hepatitis & 85 & 240 & 128 \\
\hline 2 & 50 & Active chronic hepatitis & 50 & 141 & 97 \\
\hline 3 & 56 & Active chronic hepatitis & 11 & 54 & 95 \\
\hline 4 & 51 & Active chronic hepatitis & 10 & 241 & 128 \\
\hline 5 & 63 & Active chronic hepatitis & 35 & $>250$ & 134 \\
\hline 6 & 32 & Subacute hepatic necrosis & 400 & 650 & 121 \\
\hline 7 & 46 & Subacute hepatic necrosis & 190 & 130 & 140 \\
\hline 8 & 53 & Alcoholic cirrhosis & 90 & 185 & 138 \\
\hline 9 & 53 & Alcoholic cirrhosis & 155 & 139 & 200 \\
\hline 10 & 42 & Alcoholic cirrhosis & 87 & 89 & 128 \\
\hline 11 & 53 & Alcoholic cirrhosis & 51 & 140 & 115 \\
\hline 12 & 58 & Alcoholic cirrhosis & 40 & 85 & 98 \\
\hline 13 & 44 & Alcoholic cirrhcsis & 90 & 54 & 113 \\
\hline 14 & 48 & Sarcoidosis & 11 & 25 & 80 \\
\hline 15 & 52 & Congenital erythrocytic protoporphyria & 80 & 52 & 167 \\
\hline \multicolumn{6}{|c|}{ Given a Concentrate of Factor IX } \\
\hline 16 & 53 & Active chronic hepatitis & 22 & 240 & 67 \\
\hline 17 & 63 & Active chronic hepatitis & 400 & 2050 & 109 \\
\hline 18 & 65 & Active chronic hepatitis & 88 & 216 & 113 \\
\hline 19 & 48 & Active chronic hepatitis & 24 & 80 & 102 \\
\hline 20 & 59 & Alcoholic cirrhosis & 108 & 122 & 190 \\
\hline 21 & 37 & Alcoholic cirrhosis & 27 & 75 & 112 \\
\hline 22 & 36 & Alcoholic cirrhosis & 34 & 47 & 71 \\
\hline 23 & 54 & Alcoholic cirrhosis & 60 & 113 & 76 \\
\hline 24 & 53 & Alcoholic cirrhosis & 20 & 71 & 69 \\
\hline 25 & 62 & Extrahepatic biliary obstruction & 105 & 750 & 155 \\
\hline 26 & 50 & Haemochromatosis & 22 & 96 & 109 \\
\hline 27 & 35 & Halothane-associated hepatitis & 21 & 61 & 195 \\
\hline 28 & 53 & Chronic persistent hepatitis & 94 & 66 & 127 \\
\hline 29 & 45 & Partial nodular transformation & 60 & 82 & 102 \\
\hline 30 & 37 & Cardiac fibrosis & 112 & 50 & 150 \\
\hline
\end{tabular}

Table I Clinical and biochemical data on the 30 patients studied at the time of biopsy

factors II, IX, and X, and less than 80 units of factor VII (Prothromplex, Serological Products Ltd).

Percutaneous needle liver biopsy was performed with a Trucut needle 30 min after injection of the concentrate or after the initial infusion of fresh frozen plasma. After the biopsy the patients were observed carefully for clinical evidence of bleeding. The occurrence of severe pain or tenderness was recorded, the blood pressure and pulse rate being monitored hourly for the first six hours and then four hourly for the next 18 hours. The packed cell volume was estimated before biopsy and again 24 hours later. Prothrombin time (using the Manchester thromboplastin reagent) and thrombin clotting times were performed by routine methods (Denson, 1972) and expressed as a ratio with the normal control. Platelets were counted visually. Fibrinogen was estimated by a gravimetric technique (Denson, 1972) and the level of fibrin degradation products was measured using the tanned red cell haemagglutination inhibition assay (Merskey, Lalezari, and Johnson, 1969). The levels of clotting factors II and IX were determined by a two-stage assay, and those of factors V, VII (using a patient-deficient plasma) and factor $X$ by a one-stage assay (Denson, 1972). Plasma for clotting factor assays was stored at $-20^{\circ} \mathrm{C}$ for two to three weeks and assayed in batches.

Blood samples before infusion of concentrates and between six and eight weeks afterwards were examined for hepatitis B antigen (by immunodiffusion, immunoelectrophoresis and radioimmunoassay), except in four patients who were HBAg positive before biopsy.

\section{Results}

There was no clinical evidence of bleeding in any of the patients in the two groups. No patient required a blood transfusion, although the packed cell volume dropped by $11 \%$ in one patient 24 hours after biopsy. Two patients developed superficial thrombophlebitis following extravascular injection of a small quantity of the concentrate. In 27 of the 30 patients the prothrombin time had improved when retested $30 \mathrm{~min}$ following the end of infusion of fresh frozen plasma or concentrate (fig 1). However, in only three patients receiving fresh frozen plasma and seven receiving the concentrate had the prothrombin time returned to within normal limits (three sec or less prolonged). Overall, the prothrombin time prolongations appeared slightly greater in the patients given fresh frozen plasma, although in all other 


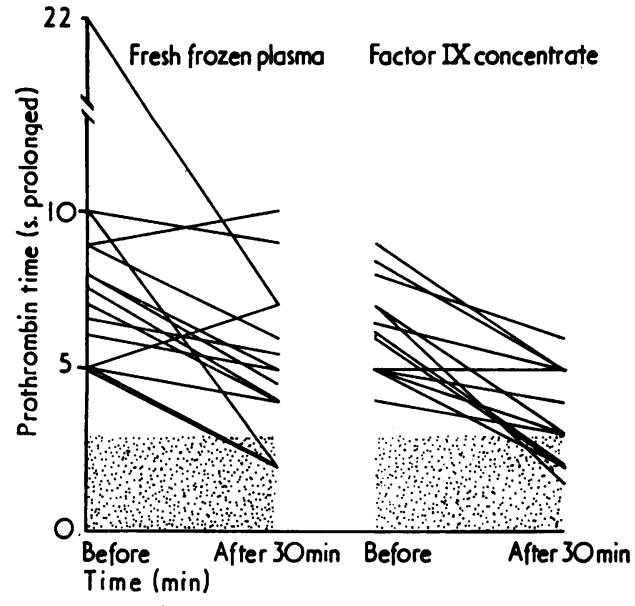

Fig 1 The prothrombin time in seconds prolonged over control immediately before biopsy and 30 min after the completion of an infusion of fresh frozen plasma or a factor IX concentrate.

respects the two groups appeared comparable.

No laboratory evidence of intravascular coagulation was detected at three min, $30 \mathrm{~min}$, six or $24 \mathrm{hr}$ following infusion of the concentrate. The thrombin clotting time was abnormally prolonged in six patients before biopsy, but these values did not rise further following the infusions. The platelet count fell by more than $20 \%$ of the initial count in only two patients, and in no case were raised levels of fibrin degradation products detected. No fall was seen in the plasma fibrinogen levels, which were always $2.0 \mathrm{~g} / \mathrm{l}$ or more.

\section{CLOTTING FACTOR ASSAYS}

Initial levels were reduced to a similar degree in both

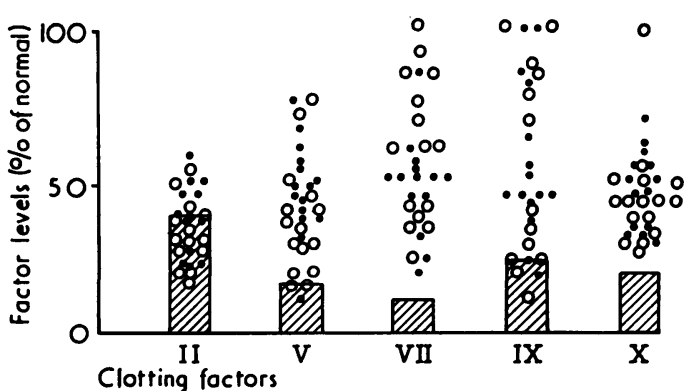

Fig 2 Levels of individual clotting factors immediately before biopsy in the 30 patients included in this study. The squares represent those patients receiving fresh frozen plasma.
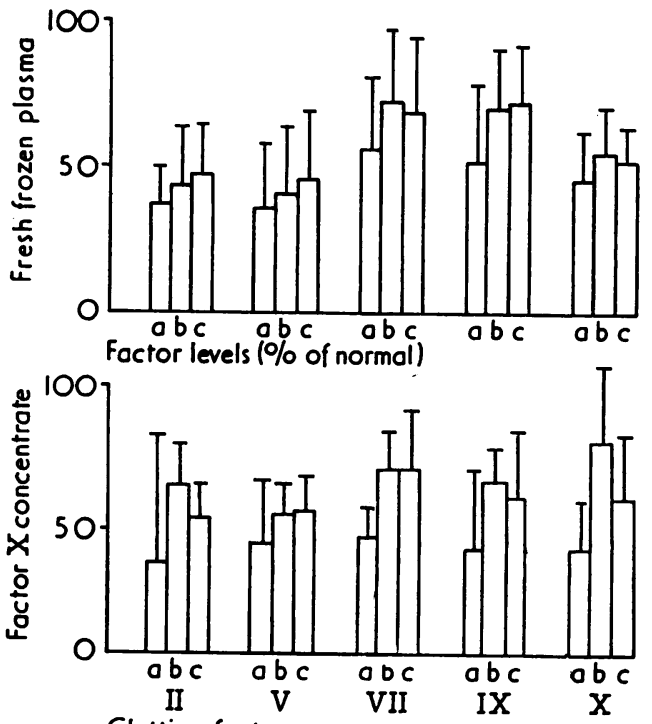

Clotting foctors

Fig 3 Mean values (and standard deviation) of clotting factor levels for the two groups of patients taken at 30 minutes (b) and 20 hours (c) following either a factor $I X$ concentrate or fresh frozen plasma infusion compared with those found before liver biopsy (a).

groups of patients and were always above $10 \%$ of the normal value (fig 2). The samples taken 30 min following the administration of fresh frozen plasma showed a rise in the levels of factors II, V, VII, IX, and $\mathrm{X}$, which was most pronounced for factors VII and IX (fig 3). The levels were still increased $24 \mathrm{hr}$ later, although there was some fall in the levels of factor VII compared with those recorded $30 \mathrm{~min}$ after infusion. The patients given the concentrate showed a considerably greater rise in levels of factors II, VII, and X. This was because more clotting factors were administered using the concentrate than with fresh frozen plasma,eg, 2000 and 600 units

\begin{tabular}{lll}
\hline Factor & $\begin{array}{l}\text { Increase in Clotting Factor Activity/kg/unit of } \\
\text { Factor Administered }(\% / \mathrm{kg})\end{array}$ \\
\cline { 2 - 3 } & Fresh Frozen Plasma & Concentrate \\
\hline II & $1.0(0.75)$ & $0.8(0.67)$ \\
V & $1.1(0.97)$ & - \\
VII & $2.0(1.6)$ & - \\
IX & $1.9(1.5)$ & $0.84(0.62)$ \\
X & $1.0(0.97)$ & $1.4(0.65)$ \\
\hline
\end{tabular}

Table II Mean increase in clotting factor activity / $k g$ body weight/unit of the factor administered produced in the two groups of patients ${ }^{1}$

${ }^{1}$ The standard deviation is also shown. 
of factor II respectively. However, when the observed increase in activity of factors II and IX was expressed per kg body weight per unit of clotting factor infused, this was greater with fresh frozen plasma than with the concentrate (table II). Neither the initial prothrombin time nor the change in this following replacement therapy could be correlated with the levels of any of the individual clotting factors.

Of eight patients given concentrate who were initially HBAg negative and in whom follow-up samples were available, one became positive by immunodiffusion eight weeks later. There was no change in clinical signs or biochemical tests at this time, but in another cirrhotic patient who became positive at four months having been negative when tested at six weeks, this was accompanied by an acute hepatitic illness. Both these patients were in the ward for about four weeks after the time of the liver biopsy, but neither of them was given additional blood or blood products. Similarly, one patient in the group given fresh frozen plasma in whom HBAg was detected by radioimmunoassay four months later developed clinical and biochemical evidence of acute hepatitis.

\section{Discussion}

Partial correction of the coagulation defect was achieved in both groups of patients and in neither were there any immediate side effects attributable to the use of these prophylactic measures. The advantage of a concentrate over fresh frozen plasma in replacement therapy is that much larger quantities of clotting factors can be administered in a small volume of fluid. One potential hazard of concentration infusion already referred to, namely, disseminated intravascular coagulation, was not observed. This may be because intravascular coagulation is already present in the patients with fulminant hepatic failure, whereas in the cirrhotics it is less constant or severe. Another possibility is that in the present cases sufficient liver function remained to clear from the circulation small amounts of activated clotting factor infused with the concentrate. Since pooled plasma is used in the preparation of the concentrate, an important potential complication is the transmission of viral hepatitis, although each donor is screened by radioimmunoassay at regular intervals and the concentrate is also tested by the same technique. Three of our patients became HBAg positive, two following infusion of concentrate and one after being given fresh frozen plasma. The plasma from which the fresh frozen plasma was prepared had also been screened for HBAg. Another possibility is that these patients acquired the virus from other patients in the ward, although in previous detailed studies of the ward we could find no convincing evidence of such cross infection (Bentley, Haynes, Sharpstone, Taylor, Zuckerman, and Williams, 1972).

The yield of factors II and IX in the circulation of our patients from the concentrate was lower than after fresh frozen plasma. This may relate to rapid clearance of clotting factors altered during the concentration process. The concentrate does not contain factor $\mathrm{V}$, but small increases were observed in the levels of this clotting factor following infusion. As the factor V-deficient plasma used in the assay may also have reduced factor II levels, increases in this following administration of the concentrate could account for the apparent rises in factor $\mathrm{V}$ recorded. Other workers have noted that concentrates of factor IX only produce partial correction of the prothrombin time in patients with cirrhosis and have attributed this to the lack of factor V in the preparation (Sandler, Rath, and Ruder, 1973). The rises in factor VII were of interest, as the concentrate only contains small amounts of this clotting factor, but other workers have also noted this effect (Dr Eibl, personal communication).

In our patients, the levels of all the clotting factors, except factor II, were above those required for haemostasis as quoted by Rizza (1972). Although the influence of multiple clotting factor deficiencies on the development of the bleeding tendency is not known, it is likely that only replacement of factor II was important in these cases. Thus, a better routine screening test for patients before liver biopsy may be the Normotest or Thrombotest which are said to be more sensitive to a reduction in factor II levels than the one-stage prothrombin time (Hadchouel, Toubouli, and Caroli, 1973). Many other factors, including platelet numbers and function and vascular fragility, may be equally important in determining the likelihood of bleeding, and whether replacing clotting factor is really worthwhile in the type of patient we studied is uncertain. Nevertheless, the risks of bleeding after biopsy in such cases, if it did occur, would be high, and so it would seem reasonable to continue to use some form of clotting factor replacement such as fresh frozen plasma, even though its value prophylactically may be difficult to prove.

B G $G$ was supported by the King's College Hospital Research Committee and J M H by Serological Products Ltd, who also supplied the concentrate. Professor A J Zuckerman kindly performed the radioimmunoassays for hepatitis $\mathbf{B}$ antigen and antibody. 
References

Bentley, P., Haynes, D., Sharpstone, P., Taylor, P. E., Zuckerman, A. J., and Williams, R. (1972). Screening for transmission of hepatitis within a liver unit. J. Hyg. (Lond.), 70, 197-202.

Denson, K. W. E. (1972). In Human Blood Coagulation, Haemostasis and Thrombosis, edited by R. Biggs, pp. 587-675. Blackwell, Oxford.

Gazzard, B. G., Lewis, M. L., Ash, G., Rizza, C. R., Bidwell, E., and Williams, R. (1974). Coagulation factor concentrate in the treatment of the haemorrhagic diathesis of fulminant hepatic failure. Gut, 5, 993-998.

Hadchouel, P., Touboul, J. P., and Caroli, J. (1973). Study on the correlation between normotest, Quick's method and specific coagulation factors in liver disease. Scand. J. Gastroent., 19, Suppl. 151-154.
Merskey, C., Lalezari, P., and Johnson, A. J. (1969). A rapid, simple, sensitive method for measuring fibrinolytic split products in human serum. Proc. Soc. exp. Biol. (N.Y.), 131, 871-875.

Rizza, C. R. (1972). In Human Blood Coagulation, Haemostasis and Thrombosis, edited by R. Biggs, pp. 333-360. Blackwell, Oxford.

Roberts, H. R., and Cederbaum, A. I. (1972). The liver and blood coagulation: physiology and pathology. Gastroenterology, 63, 297-320.

Sandler, S. G., Rath, C. E., and Ruder, A. (1973). Prothrombin complex concentrates in acquired hypoprothrombinemia. Ann. intern. Med., 79, 485-491.

Sherlock, S. (1968). In Diseases of the Liver and Biliary System, 4th ed., p. 53. Blackwell, Oxford.

\section{The July 1975 Issue}

\section{THE JULY 1975 ISSUE CONTAINS THE FOLLOWING PAPERS}

Aspects of the effect of metiamide on pentagastrinstimulated and basal gastric secretion of acid and pepsin in man B. THJODLEIFSSON AND K. G. WORMSLEY

Gastric emptying following vagotomy and antrectomy and proximal gastric vagotomy H. KALBASI, F. R. HUDSON, A. HERRING, S. MOSS, H. I. GLASS, AND J. SPENCER

Electronmicroscopic observations on the effects of orally administered aspirin and aspirin-bicarbonate mixtures on the development of gastric mucosal damage in the rat $\mathrm{K}$. D. RAINSFORD

A search for a transmissible agent in Crohn's disease RICHARD V. HEATLEY, P. M. BOLTON, E. OWEN, W. JONES WILLIAMS, AND L. E. HUGHES

\section{A case of 'Crohn's carcinoma' K. A. FLEMING AND A. C. POLLOCK}

The immune response to $Ø X 174$ in man. III. Evidence for an association between hyposplenism and immunodeficiency in patients with coeliac disease P. G. BAKER, J. VERRIER JONES, D. B. PEACOCK, AND A. E. READ
Regional differences in oxalate absorption by rat intestine: Evidence for excessive absorption by the colon in steatorrhoea D. R. SAUNDERS, J. SILLERY, AND G. B. MCDONALD

The relative potency of the Crick-Harper-Raper unit and the GIH clinical unit of secretion JOAN M. BRAGANZA, HENRY T. HOWAT, AND G. KAY

The Paneth cell: A source of intestinal lysozyme T. PEETERS AND G. VANTRAPPEN

Disodium cromoglycate in the treatment of chronic proctitis R. V. HEATLEY, B. J. CALCRAFT, J. RHODES, E. OWEN, AND B. K. EVANS

\section{Progress report}

Duodenal ulcer in black populations in Africa south of the Sahara F. I. TOVEY AND M. TUNSTALL

Notes and activities

Notes on books

Copies are still available and may be obtained from the PUBLISHING MANAGER, BRITISH MEDICAL ASSOCIATION, TAVISTOCK SQUARE, LONDON WC1H 9JR, price $£ 2 \cdot 00$, including postage 